\title{
Expansão da matriz hidrelétrica brasileira: uma análise a partir da economia dos bens e serviços públicos
}

\section{The Brazilian hidropower plants expansion: an analysis since the economy of goods and public services}

Alexandre do Nascimento Souza - Professor do Curso de Gestão Ambiental da Escola de Artes, Ciências e Humanidades da USP (EACH/USP). Mestre e Doutor pelo Programa de Pós Graduação em Ciência Ambiental (PROCAM/IEE) da Universidade de São Paulo. Email: alenascimento@usp.br

Pedro Roberto Jacobi - Professor titular da Faculdade de Educação e do Programa de Pós-Graduação em Ciência Ambiental (PROCAM/IEE/USP); coordenador de Grupo Temático Governança Ambiental do INCLINE; coordenador de GovAmb/USP; Editor da revista Ambiente e Sociedade. E-mail: prjacobi@usp.br

\begin{abstract}
Resumo
O trabalho analisa a expansão da matriz hidrelétrica a partir da discussão proposta pela economia pública, e tem como base o planejamento do setor elétrico brasileiro até 2030. Reflete o potencial de aumento dos conflitos socioambientais relacionados à construção de hidrelétricas na Amazônia. Nos próximos 20 anos, o planejamento do setor elétrico prevê que a bacia do rio Amazonas seja responsável por cerca de $77 \%$ da expansão da matriz elétrica brasileira. No entanto, $62 \%$ do potencial da bacia tem restrições socioambientais, segundo o critérios do organismo planejador. Os avanços recentes em relação ao trato das questões socioambientais relacionadas à construção de hidrelétricas se dão em função da mobilização e articulação do movimento social, ONGs ambientalistas e da participação ativa do Ministério Público. $\mathrm{O}$ artigo conclui que o ambiente conflituoso presente no setor elétrico é consequência da falta de participação social nas instâncias decisórias do planejamento do setor elétrico.
\end{abstract}

\section{Palavras-chave}

Hidrelétricas. Conflitos socioambientais. Economia pública.

\begin{abstract}
This work makes an analysis of the hydropower plants expansion since the public economy framework. We use the electrical sector planning until 2030 to built the analysis. The research reflects the socioenvironmental conflicts related the hydropower plants construction in the Amazonia region. In the next 20 years, the electrical sector planning expects that the Amazonas River Basin will be responsible for $77 \%$ of the hydropower plant expansion in Brazil. However, around $62 \%$ of it has some socioenvironmental restriction, in according of planners. Recently, the advances in the sector happened because of social movement, environmental NGOs and Public Minister mobilization and articulation. The article concludes that the conflicting environment in the electrical sector expansion is consequence of the lack of social participation in the decision making process in the sector.
\end{abstract}

\section{Keywords}

Hydropower plants. Socioenvironmental conflicts. Public economy. 


\section{INTRODUÇÃO}

A presença de hidrelétricas na matriz elétrica brasileira ganhou impulso a partir dos anos 1970, quando o país viveu sob a égide de uma ditadura militar. Entre os anos de 1974 e 2004, a potência instalada em usinas hidrelétricas cresceu mais de 400\%, passando de 13.274 MW para 69.000 MW (BRASIL, 2007).

A expansão dos empreendimentos hidrelétricos nos últimos 30 anos do século XX, se por um lado garantiu o suprimento de eletricidade necessária à industrialização e urbanização do Brasil, teve como contrapartida empreendimentos polêmicos, e que não se justificam do ponto de vista dos impactos gerados e da quantidade de energia que produzem. As hidrelétricas de Balbina e Tucuruí são questionadas internacionalmente em função dos impactos socioambientais gerados (WCD, 2000; MILARÉ, 2004).

As duas hidrelétricas também são a síntese de um comportamento que via no interesse do Estado a justificativa para a falta de discussão com setores alheios ao setor elétrico. O princípio que orientou o planejamento militar para a expansão da hidroeletricidade no Brasil desabrigou e empobreceu milhares de ribeirinhos, agricultores familiares e trabalhadores rurais que, deslegitimados de seus direitos e desprovidos de canais democráticos para reivindicar a reparação de seus modos de vida, organizaram-se em torno do movimento dos atingidos por barragens ${ }^{1}$ (SIGAUD, 1986; CASTRO, 1988, BERMANN, 1993; VAINER, 2007).

O processo de democratização da sociedade brasileira também incidiu sobre o setor elétrico, no entanto, os problemas relacionados aos impactos socioambientais, a reparação e mitigação dos mesmos pouco mudou, e parte dos avanços no discurso do setor elétrico retroagiram (VAINER, 2003; BANCO MUNDIAL, 2008).

A consolidação da democracia na Constituição Cidadã de $1988^{2}$ e a criação de inúmeros canais de participação social (DAGNINO, 1994; AVRITZER, 2002; DAGNINO, 2002; TATAGIBA, 2002), assim como a legitimação do Ministério Público como defensor do meio ambiente e dos interesses difusos ampliou o debate e ofereceu instrumentos legais para a manifestação dos conflitos

\footnotetext{
O Movimento dos Atingidos por Barragens consolidou-se nacionalmente desde 1980. "A história dos atingidos por barragens no Brasil tem sido marcada pela resistência na terra, luta pela natureza preservada e pela construção de um projeto popular para o Brasil que contemple uma nova Política Energética justa, participativa, democrática e que atenda aos anseios das populações atingidas, de forma que estas tenham participação nas decisões sobre o processo de construção de barragens, seu destino e o do meio ambiente". Disponível em: <www. mabnacional.org.br/historia.html>. Acesso em: 13 set. 2009.

2 A Constituição de 1988 consolidou a normalidade democrática na sociedade brasileira. Embora até hoje não esteja completamente regulamentada, é um marco no processo de redemocratização, sobretudo por prever inúmeros canais de participação social.
} 
relacionados à geração hidrelétrica no Brasil (CONGRESSO NACIONAL, 1988; SOUZA, 2009).

O Brasil detém cerca de 78.000 MW de potência instalada em suas hidrelétricas. O Plano Nacional de Energia (BRASIL, 2007) trabalha com a perspectiva de cerca de 250.000 MW instalados na matriz elétrica em 2030. Espera-se que a bacia do rio Amazonas produza 77\% do planejado para ser incorporado ao sistema elétrico, embora $62 \%$ do potencial tenha alguma restrição socioambiental.

Populações atingidas, ONGs, Ministério Público e pesquisadores têm apontado problemas nos Estudos de Impacto Ambiental de UHEs, e denunciam a falta de diálogo e de medidas compensatórias justas para os atingidos, além de desrespeito às interações simbólicas entre o ser humano e o ambiente, etc. (SANCHÉZ, 2006; SWITKES, 2008; MAGALHÃES; HERNANDEZ, 2009).

Osnovos projetosnaAmazôniaincorporarampreocupações socioambientais inexistentes nos empreendimentos anteriores. Os empreendimentos do rio Madeira (Jirau e Santo Antonio) preveem menor volume de água acumulada do que o previsto anteriormente para os períodos de menor vazão do rio. Em Belo Monte, para conseguir melhor viabilidade ambiental, o governo abriu mão da utilização de outros aproveitamentos hidrelétricos no rio Xingu, assim como reviu plantas de projetos de hidrelétricas a serem construídas nos rios Tocantins, Tapajós e Araguaia, diminuindo o tamanho dos reservatórios ou tornando-os empreendimentos hidrelétricos a fio d'água, quando não há reservatório para estocar água e toda a produção de hidroeletricidade é feita com o fluxo do rio (TUNDISI et al., 2014).

Apesar dos esforços governamentais empreendidos a partir de 2004, com o estabelecimento de inúmeros fóruns de discussão com os principais atores sociais envolvidos nos conflitos relacionados à construção de hidrelétricas (SOUZA, 2009), os processos de licenciamento das três hidrelétricas demonstram que persistem comportamentos antigos do setor elétrico, apontados no relatório da Comissão Mundial de Barragens (WCD, 2000).

Diante do fato de que, mesmo depois de o governo brasileiro promover mudanças no processo de planejamento da expansão da matriz hidrelétrica, com a criação da Empresa de Pesquisa Energética- EPE (SOUZA, 2009), e de refazer os projetos das hidrelétricas a serem construídas na Amazônia (SOUZA; JACOBI, 2013), mantém-se o ambiente de conflito em torno da produção de energia hidroelétrica. Acreditamos que se fazem necessárias novas reflexões que possam identificar por que persistem o ambiente de conflito e a inexistência de acordos que garantam, por um lado, a expansão da produção de energia; e, por outro, a satisfação das necessidades das comunidades atingidas pelos empreendimentos 
hidroelétricos. Neste artigo apresentamos uma análise do planejamento da expansão da matriz hidroelétrica à luz dos pressupostos da economia pública (OSTROM, V.; OSTROM, 1999; OAKERSON, 1999). Neste sentido, discutimos o planejamento da produção de energia elétrica tomando como referência a participação social na provisão da produção de bens e serviços públicos.

\section{A ECONOMIA PÚBLICA - UMA ABORDAGEM POLICÊNTRICA DA PRODUÇÃO E FRUIÇÃO DOS BENS E SERVIÇOS PÚBLICOS}

De acordo com Ostrom, V. e Ostrom (1999), a economia pública não precisa necessariamente ser exercida como um monopólio estatal. Neste sentido, a prestação dos serviços públicos poderia também ser realizada com a participação do capital privado. No entanto, a participação do capital privado na prestação de serviços públicos adquire uma lógica diferente daquela, na qual o setor privado originalmente atua na comercialização de bens privados. Para Ostrom (2010), os seres humanos têm desenvolvido complexos sistemas privados, governamentais e comunitários que, ao mesmo tempo em que são produtivos e inovadores, podem ser destrutivos e obter resultados indesejados. Quando os indivíduos utilizam recursos naturais comuns de forma anônima e isolada, tendem a fazer o uso de forma exagerada, acima das suas necessidades ou mesmo da capacidade de uso do recurso. No entanto, quando confrontados com níveis mínimos de informação, mudam o comportamento e passam a utilizar os recursos de maneira mais racional, orientados pela perspectiva de uso mais duradouro. A economista americana apresenta resultados de pesquisas desenvolvidas no Nepal com sistemas de irrigação, que desafiam a crença de que os governos estão mais capacitados para a gestão de recursos comuns do que quando os usuários decidem organizar o uso comum e proteger os recursos de uma possível degradação.

Em oposição à ideia de que é necessária uma hierarquia central na provisão de bens e serviços públicos, estudos desenvolvidos na Califórnia, nos anos 1960, constataram que múltiplos agentes públicos e privados, atuando concomitantemente, foram capazes de organizar o suprimento da demanda por água. De acordo com esses estudos, em áreas metropolitanas policêntricas, a produtividade de bens e serviços públicos aumenta, pois: (1) pequenas e médias cidades têm melhores condições para monitorar a performance dos cidadãos e os custos relevantes de provisão dos bens e serviços públicos; (2) cidadãos insatisfeitos com o atendimento de suas demandas podem optar por jurisdições que estejam mais próximas das suas preferências; (3) comunidades locais podem contratar a prestação de serviços, à medida em que não estejam satisfeitas, 
podem mudar de fornecedores. Áreas metropolitanas, com um grande número de produtores de bens e serviços públicos alcançaram altos níveis de eficiência tecnológica (OSTROM, 2010).

\subsection{SOBRE FORMAS DE ORGANIZAÇÃO E TIPOS DE BENS}

$\mathrm{Na}$ tentativa de conceituar a provisão dos bens e serviços públicos em uma economia policêntrica, Elinor Ostrom (2010) sistematiza princípios que a teoria econômica tem utilizado, para depois propor a sua revisão, de acordo com a nova perspectiva adotada.

Por um lado, o mercado é considerado a instituição adequada para a produção e comercialização de bens privados; por outro, o mainstream econômico considera que cabe ao governo controlar a produção e a provisão de bens e serviços públicos, assim como decidir a maneira como os cidadãos irão usufruir desses bens, inclusive definindo as regras e taxas que regulam o acesso destes às suas demandas. Em síntese, cabe ao governo decidir de forma centralizada, e a partir de uma estrutura de comando hierarquizada, a satisfação da demanda por bens e serviços públicos.

Bens públicos são entendidos como aqueles que autoridade gestora não $e ́$ capaz de impedir que amplas parcelas da sociedade tenham acesso (impossibilidade de excluir alguém) e usufruam coletivamente (um uso não impede o outro, não há competição pelo uso). Uma vez produzidos, independente de os indivíduos estarem dispostos a pagar ou mesmo querer se submeter a regras previamente impostas, todos podem utilizá-los. Essas características dos bens públicos se diferenciam dos bem privados, uma vez que estes podem ter o acesso controlado, ou seja, quem não paga ou não respeita as regras não irá usufruí-los (possibilidade de excluir); e quando um indivíduo utiliza o bem, impossibilita que outros o utilizem (um uso impede o outro, há competição pelo uso) (OSTROM, 2010; OSTROM, V.; OSTROM, 1999).

As características dos bens públicos colocam em xeque presunções da racionalidade econômica e da teoria dos jogos, que acreditam que toda ação estratégica de um indivíduo é direcionada a maximizar os resultados esperados a partir de: (1) conhecimento de todas as estratégias possíveis em uma situação em particular; (2) quais resultados esperar de cada uma das estratégias possíveis, levando-se em conta o comportamento de outros atores na mesma situação; (3) classificação dos resultados que podem ser melhores, tendo em vista as estratégias possíveis (OSTROM, 2010). 
Em oposição à divisão dos bens em públicos e privados, Ostrom (2010) propõe que em uma economia policêntrica os bens sejam classificados em relação às suas características de competição no uso do bem e a possibilidade de excluir potenciais beneficiários, em escalas que vão da menor até a maior possibilidade.

\section{HIDRELÉTRICAS NO BRASIL - A NECESSIDADE DA EXPANSÃO $\mathrm{X}$ CONFLITOS SOCIOAMBIENTAIS}

O Brasil tem cerca de 78.000 MW de potência instalada em suas hidrelétricas. O Plano Nacional de Energia trabalha com a perspectiva de ter entre 210.000 e 250.000 MW instalados na matriz elétrica brasileira em 2030 .

A expansão hidrelétrica prevista para o período é de pouco mais de 95.000 MW. Deste total, o PNE espera que a bacia do rio Amazonas produza 77\% do que está planejado para ser incorporado ao sistema elétrico brasileiro, conforme a Figura 1. Embora esta bacia tenha 77.000 MW de potencial hidrelétrico, 62\% tem algum tipo restrição socioambiental ${ }^{3}$ (Tabela 1).

Figura 1 - UHEs planejadas para a Amazônia.

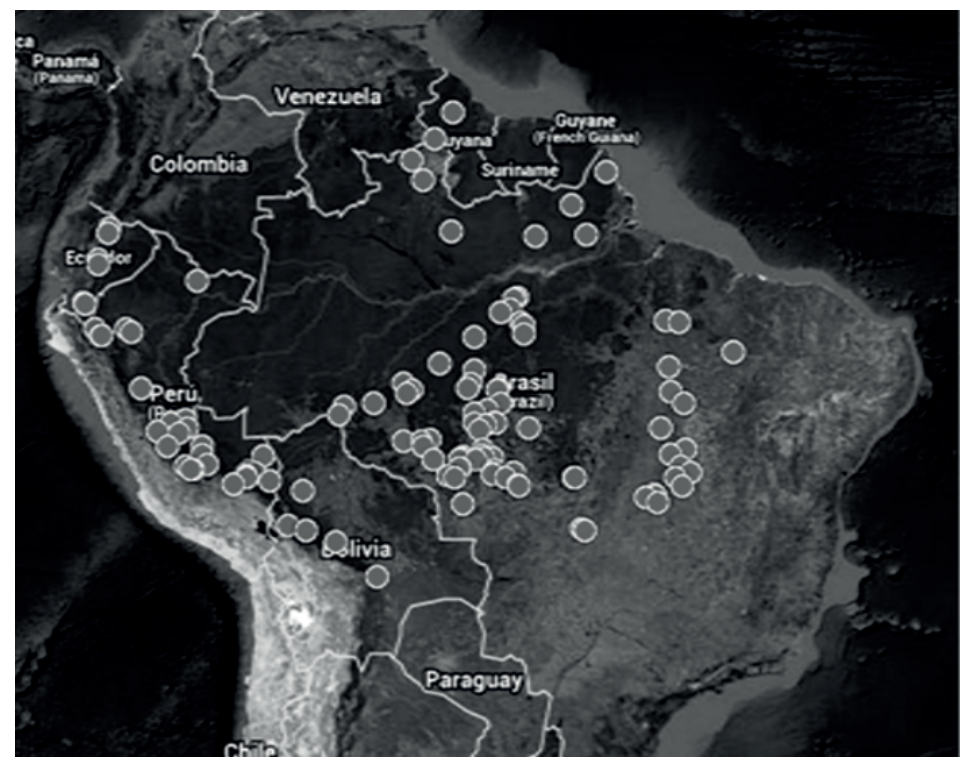

Fonte: Extraído de Tundisi et al. (2014).

\footnotetext{
Os impactos socioambientais considerados para a bacia do Amazonas foram: cidades, área populosa, floresta nacional, parque nacional, reserva indígena, área de quilombo, área de proteção ambiental, reserva biológica, reserva de desenvolvimento sustentável, rio virgem, tamanho da área alagada, área de elevado custo de terra, interferência com infraestrutura de significativa expressão econômica - ferrovias, rodovias, etc. (BRASIL, 2007).
} 
Tabela 1 - Potencial de geração dos recursos hídricos (MW).

\begin{tabular}{l|c|c|c|c}
\hline & $\begin{array}{c}\text { Bacia } \\
\text { Amazonas }\end{array}$ & $\begin{array}{c}\text { Bacia Tocantins/ } \\
\text { Araguaia }\end{array}$ & $\begin{array}{c}\text { Demais } \\
\text { Bacias }\end{array}$ & Total \\
\hline Potencial aproveitado & 835 & 12.198 & 64.744 & 77.777 \\
\hline Expansão potencial até 2015 & 12.153 & 2.428 & 5.563 & 20.244 \\
\hline Expansão potencial 2015-2020 & 16.943 & 1.600 & 5.000 & 23.543 \\
\hline Expansão potencial 2020-2030 & 44.200 & 3.200 & 5.000 & 52.400 \\
\hline Total & 74.231 & 19.426 & 80.307 & 173.964 \\
\hline
\end{tabular}

Fonte: Dados extraídos de Brasil (2007).

O percentual com restrição de uso do potencial hidrelétrico não significa necessariamente que o mesmo não possa ser utilizado, mas os atuais planejadores do setor elétrico brasileiro esperam que uma bacia com potencial de aproveitamento de cerca de 77.000 MW contribua com 73.000 MW nos próximos 20 anos, embora estejam cientes de que 47.862 MW têm alguma restrição à sua utilização, conforme a Tabela 2 .

Tabela 2 - Bacia do Amazonas - caracterização do potencial hidrelétrico segundo os impactos ambientais (MW)

\begin{tabular}{l|r|c}
\hline Impacto & Total & \% \\
\hline Sem impacto significativo & 29.196 & 37,9 \\
\hline Reserva indígena & 34.158 & 44,3 \\
\hline Parque nacional & 9.330 & 12,1 \\
\hline Quilombo & 2.883 & 3,7 \\
\hline Reserva de desenvolvimento sustentável & 968 & 1,3 \\
\hline Floresta nacional & 420 & 0,5 \\
\hline Área de preservação ambiental (APA) & 53 & 0,1 \\
\hline Reserva biológica & 50 & 0,1 \\
\hline Demais impactos $\left(^{*}\right)$ & & $<0,5$ \\
\hline
\end{tabular}

Fonte: Dados extraídos de Brasil (2007).

De acordo com os dados extraídos do PNE 2030 e expostos nas Tabelas 1 e 2, a expansão da matriz hidrelétrica brasileira cresce a probabilidade de acirramento dos conflitos, pois a bacia do rio Amazonas, além das restrições, fruto da legislação ambiental, tem grande potencial de mobilizar ONGs nacionais e internacionais, além da oposição dos grupos indígenas, uma vez que 44\% do potencial a ser aproveitado encontra-se em terras indígenas. 
A percepção das dificuldades de se construir grandes empreendimentos hidrelétricos na Amazônia tem levado o governo brasileiro a rever os projetos já planejados, na perspectiva de torná-los menos impactantes (TUNDISI et al., 2014).

Os projetos das hidrelétricas do rio Madeira foram revistos e terão menor volume de regularização da vazão. $\mathrm{O}$ aproveitamento do rio Xingu, que previa anteriormente mais de uma central hidrelétrica foi revisado, e no estudo de impacto ambiental apresentado para o processo de licenciamento ambiental, o governo brasileiro se comprometeu a abrir mão dos demais projetos hidrelétricos previstos para aquele rio (SOUZA; JACOBI, 2013).

Ao abrir mão de parte do potencial hidrelétrico para que os projetos tenham maior viabilidade socioambiental, os planejadores da expansão do setor esperam compensar a perda com a inclusão de mais termoelétricas e outras fontes - Eólica, PCH e Biomassa na matriz elétrica (TUNDISI et al., 2014; BRASIL, 2007). A previsão é de que em 2030 as hidrelétricas respondam por $78 \%$ da matriz elétrica, contra 85\% em 2008 (BRASIL, 2007).

\section{HIDRELÉTRICAS NA AMAZÔNIA: JIRAU, SANTO ANTÔNIO E BELO MONTE}

Apesar dos esforços do governo brasileiro em rever os projetos hidrelétricos do rio Madeira e Belo Monte, a observação dos processos de licenciamento da hidrelétrica de Jirau, no rio Madeira; e da hidrelétrica de Belo Monte, no Rio Xingu, demonstram que ainda persistem muitos comportamentos que datam de quatro décadas atrás. Algumas das críticas que se fazem aos projetos e a forma com que foram apresentados à sociedade têm muita semelhança com problemas identificados pelo relatório da Comissão Mundial de Barragens (WCD, 2000).

Os dois projetos do rio Madeira foram retomados pelo governo do presidente Lula e sofreram modificações técnicas para diminuir os impactos socioambientais. Em função dessa orientação, os empreendimentos preveem menor volume de água acumulada do que foi anteriormente previsto para os períodos de menor vazão do rio. No caso da UHE Belo Monte, para garantir a sua viabilidade ambiental, o governo se comprometeu, no âmbito dos estudos de impacto ambiental, a abrir mão da utilização de outros possíveis aproveitamentos inventariados.

No entanto, a mudança do eixo da barragem proposto pelos estudos ambientais em Jirau, depois de aprovado pelo órgão ambiental, bem como o conflituoso licenciamento ambiental da hidrelétrica de Belo Monte suscitam dúvidas quanto à melhoria no trato das questões socioambientais, conforme o previsto quando da criação da EPE. O aproveitamento hidrelétrico de Jirau só foi 
a leilão depois de emitida a licença prévia, a partir dos estudos socioambientais coordenados pela EPE. Contudo, o consórcio vencedor da licitação mudou a localização do eixo da barragem em $7 \mathrm{~km}$. A situação sugere dois tipos de reflexão:

I. Os estudos contratados pela EPE não são bons e a alternativa locacional não foi a mais adequada;

II. Os estudos contratados pela EPE que orientaram o edital eram bons e corretos, no entanto, o consórcio liderado pelo grupo franco-belga Suez seguiu uma lógica muito presente no setor elétrico, de orientar a localização dos empreendimentos apenas por critérios econômicos.

A mudança da localização do empreendimento gerou dúvidas quanto à competência da EPE na coordenação dos estudos de impacto, que, no caso das usinas do rio Madeira, foram realizados por um consórcio entre a Construtora Norberto Odebrecht e uma estatal brasileira do setor elétrico, Furnas.

Antes mesmo das mudanças no projeto, feitas pelo consórcio vencedor da licitação, os estudos ambientais das hidrelétricas do rio Madeira apresentados para obtenção da licença prévia, receberam parecer contrário da equipe de analistas do IBAMA ${ }^{4}$. Durante o trâmite do processo de licenciamento, o órgão de licenciamento ficou sob forte pressão política, que culminou com a reformulação administrativa do órgão e demissão do diretor de licenciamento da instituição (SWITKES, 2008).

Os estudos ambientais do aproveitamento hidrelétrico de Belo Monte foram coordenados pela estatal Eletronorte ${ }^{5}$, que contratou algumas das maiores construtoras do país - Andrade Gutierrez, Camargo Corrêa e Norberto Odebrecht ${ }^{6}$ para a elaboração do EIA.

Os estudos socioambientais apresentados aos órgãos de licenciamento foram contestados por especialistas, ambientalistas e comunidades indígenas. No processo de legalização do licenciamento também houve contestações, uma vez que as audiências públicas foram realizadas sem a garantia de participação de todas as comunidades atingidas, o que motivou a realização de outras plenárias.

Um grupo de 38 especialistas brasileiros, entre autores e colaboradores de diversas áreas do conhecimento: ciências sociais, biologia, zoologia, energia, economia e saúde pública, elaborou uma análise crítica do estudo de impacto ambiental do aproveitamento hidrelétrico de Belo Monte (MAGALHÃES; HERNANDEZ, 2009).

\footnotetext{
4 No Brasil, o licenciamento ambiental pode ser feito nas esferas federal, estadual e municipal. Os grandes projetos hidrelétricos geralmente são licenciados, na esfera federal, pelo IBAMA (Instituto Brasileiro de Meio Ambiente).

5 A Eletronorte foi a empresa responsável pelo planejamento das hidrelétricas de Tucuruí e Balbina, ambas questionadas em função dos impactos ambientais causados.

6 As três construtoras estão entre as cinco maiores empresas de construção civil do país.
} 
O trabalho intitulado "Painel de Especialistas: Análise Crítica do Estudo de Impacto Ambiental do Aproveitamento Hidrelétrico de Belo Monte" levantou uma série de questionamentos em relação ao trabalho entregue pela estatal Eletronorte para conseguir a licença ambiental.

De acordo com o painel, o EIA da hidrelétrica de Belo Monte repete uma série de falhas que são comuns a inúmeros estudos de impacto ambiental de hidrelétricas construídas no passado: subdimensionamento das populações atingidas, podendo chegar ao dobro do total previsto no estudo; invisibilidade das especificidades socioculturais dos diversos grupos sociais; subdimensionamento da população que deverá se deslocar para a região em função do empreendimento; negligência das perdas imateriais e dos impactos sobre os modos de vida das populações locais, etc.

Do ponto de vista dos impactos sociais, o painel de especialistas defende que os estudos apresentados pela Eletronorte não são seguros, pois desconhecem a as fontes teóricas e a bibliografia sobre a Amazônia e a falta de clareza dos critérios metodológicos que nortearam os estudos.

\section{A ECONOMIA PÚBLICA}

A economia pública é diferente da economia de mercado. $\mathrm{Na}$ economia pública, a unidade básica de provisão são instituições de interesse público ${ }^{7}$, normalmente governos locais, mas também podem ser interesses privados organizados em torno de uma associação de proprietários de algum bem ou mesmo uma comunidade, por exemplo. Por princípio, uma instituição de interesse público pode contratar um produto de qualquer outra instituição de interesse público ou mesmo de empresas privadas, uma vez que tem autonomia para gerir a sua produção e/ou contratá-la. No primeiro caso, normalmente a produção é gerida a partir de uma estrutura hierarquizada. Contratos realizados neste contexto, embora sejam uma forma de regular trocas econômicas, o fazem sob uma lógica permeada também pela política, uma vez que, em geral, ao menos uma das partes é governamental e, portanto, comprometida com os cidadãos que representam e lhe dão legitimidade. As regras que orientam as relações em uma economia pública são produzidas no âmbito da política, normalmente por legisladores estatais. A governança de uma economia pública é uma meta política carregada de sentidos políticos (OAKERSON, 1999).

Comunidades locais estão mais expostas aos movimentos de empresas privadas e indivíduos mais do que uma comunidade nacional, no entanto, governos

Oakerson utiliza o termo "public households". 
locais podem ser um elemento dificultador ou facilitador do desenvolvimento econômico local, com vista a atender as demandas da comunidade à qual está relacionado (OAKERSON, 1999).

Em uma economia pública, o cidadão tem poder semelhante ao do consumidor em uma economia de mercado. Neste sentido, a variedade de produtos e serviços requeridos tem um papel importante na satisfação da demanda apresentada pelos cidadãos. Neste sentido, o monopólio, seja estatal ou privado, mina o poder do cidadão, no que diz respeito à satisfação de seus interesses. Oakerson (1999) chama a atenção para a possibilidade de os cidadãos poderem optar por uma variedade de produtos e serviços, mas também dos arranjos que serão levados a cabo para a produção e provisão.

A unidade básica de análise em uma economia pública são os cidadãos, enquanto membros de uma comunidade. A economia de mercado trata cada família como um consumidor, e a economia pública reconhece que em uma instituição de interesse público, os indivíduos são independentes, portanto, mesmo que partícipes de uma comunidade são assegurados os seus direitos e liberdades fundamentais. Desse modo, os cidadãos não são vistos somente enquanto consumidores, mas também como gestores em uma economia pública, neste caso, o exercício da cidadania está além do ato de votar para eleger os governantes, e se estende ao processo de tomada de decisão quanto às políticas públicas e ações de seu interesse. A produtividade tem relação direta com o envolvimento e proximidade do cidadão e um espírito de cidadania, em detrimento do de consumidor (OAKERSON, 1999).

A partir da perspectiva do cidadão, enquanto um tomador de decisão, a reflexão sobre o contexto no qual o consumidor passa a ter prerrogativas de cidadania torna-se imperativo, pois a tomada de decisão tem inputs diferentes do consumo.

\section{A PRODUÇÃO DA HIDROELETRICIDADE NO BRASIL: UMA ANÁLISE A PARTIR DA ECONOMIA DE BENS PÚBLICOS}

Nos anos 1990, a dificuldade do Estado brasileiro em financiar a construção de novos empreendimentos hidrelétricos impulsionou grandes mudanças no setor elétrico (OLIVEIRA, 2005; BRASIL, 2007). A primeira reformulação do setor abriu ao capital privado a possibilidade de participar da expansão deste segmento, até então restrito aos investimentos estatais. A lei 9.074/95, que tratou das concessões e permissões de serviços públicos e o decreto 2003/96, que regulamentou a produção de energia elétrica por produtor independente e 
autoprodutor promoveram uma série de transformações no setor de geração de energia elétrica (BRASIL, 2005).

O novo arranjo permitiu que agentes econômicos privados pudessem participar do incremento do parque gerador de energia elétrica. A abertura ocorrida durante o governo do presidente Fernando Henrique Cardoso trouxe a possibilidade de o capital privado investir na geração, mas não conseguiu evitar o apagão de 2001. Toda a sociedade foi compulsoriamente levada a diminuir o consumo de energia (SAUER, 2003; SOUZA, 2009).

Alguns motivos concorreram para que houvesse o racionamento de energia, e um deles foi o fato de que muitos dos empreendimentos licitados e concedidos ou não obtiveram a licença ambiental ou demoraram a obtê-la, prejudicando a disponibilidade de energia no sistema, que não adicionou novos MW à rede, como planejado ${ }^{8}$.

Em 2004, o governo brasileiro, dessa vez sob a gestão do presidente Lula, promoveu novas mudanças no setor elétrico do país. As leis 10.847/2004 e 10.848/2004 trouxeram duas novas situações que incidiram diretamente no licenciamento de empreendimentos hidrelétricos:

1. Criação da EPE (Empresa de Pesquisa Energética), pela lei 10.847, ficando encarregada de fazer estudos e pesquisas destinadas a subsidiar o planejamento do setor energético. Cabe a EPE a realização da avaliação ambiental integrada do conjunto dos empreendimentos hidrelétricos previstos para as bacias hidrográficas";

2. Os empreendimentos hidrelétricos só poderão ir a leilão depois de obtida a licença prévia (LP), a primeira de um conjunto de três licenças ambientais necessárias à instalação e operação de empreendimentos hidrelétricos.

As mudanças na legislação do setor elétrico brasileiro nos anos 1990 e 2000 contribuíram para a coexistência de conflitos de origens diversas, em relação à construção de hidrelétricas no Brasil. As mudanças promovidas nos anos 1990, na prática diminuíram a participação do Estado no planejamento da expansão do setor elétrico. A entrada do capital privado no planejamento e gestão das novas hidrelétricas trouxe de volta uma série de problemas relacionados aos empreendimentos: primazia da racionalidade técnica e econômica, relacionamento conturbado com as comunidades atingidas, agenda ambiental em

8 Em entrevista ao Caderno Setorial Energia do jornal Valor Econômico (2004), a então ministra das Minas e Energia, Dilma Roussef, afirmou que em 2004 havia 45 hidrelétricas já licitadas pelo governo FHC e que tinham problemas ambientais. Destas, 24 tinham sérios problemas.

9 A avaliação ambiental integrada é uma reivindicação antiga dos ambientalistas em relação ao planejamento do setor elétrico que até então era feito de empreendimento em empreendimento, sem buscar identificar os impactos sinérgicos que um conjunto de hidrelétricas presentes em uma mesma bacia poderiam causar. 
segundo plano e falta de visão sistêmica sobre os impactos socioambientais dos empreendimentos.

A pressão exercida pelo movimento social na década de 1980 teve como resultado o reconhecimento da necessidade da inclusão de variáveis sociais e ambientais na prática dos organismos estatais planejadores do setor elétrico, que retroagiram com a entrada do capital privado (VAINER, 2007). As mudanças ocorridas em 2004 restabeleceram a participação mais efetiva de órgãos estatais no planejamento do setor elétrico e retomaram o interesse de o Estado como importante balizador da expansão hidrelétrica. No entanto, não se resolveu o ambiente conflituoso em torno da construção de novas usinas hidroelétricas.

Quando tomamos como ponto de partida da análise o ambiente de conflito que tem caracterizado os empreendimentos hidrelétricos é possível constatar que falta participação social no planejamento execução dos empreendimentos do setor. Se por um lado o Estado retomou a prerrogativa de liderar o planejamento a partir de 2004, e o setor privado ficou com a incumbência de construir e operar os novos empreendimentos a partir dos anos de 1990, por outro, a sociedade tem tido papel secundário. Ainda que possa se posicionar por meio das audiências públicas durante os processos de licenciamento ambiental; ou mesmo nas consultas públicas realizadas pela EPE, quando do planejamento do setor elétrico, essa participação ocorre sem que se conceda poder suficiente para influenciar os rumos do setor, pois é meramente consultiva. No caso do licenciamento ambiental, a participação ocorre em um momento tardio, quando as principais decisões como a localização e tamanho dos empreendimentos já estão tomadas (SOUZA, 2009).

Outro aspecto relacionado a esta situação diz respeito à maneira como são tratadas as comunidades atingidas. Não há um amplo debate acerca dos programas compensatórios e/ou mitigatórios destinados a reparar os possíveis danos causados às comunidades atingidas pelos empreendimentos. Não há processos de negociação que busquem pactuar o caráter e dimensão dos programas. Dessa forma, os conflitos são a consequência de um processo decisório no qual a sociedade está alijada, ou seja, não exerce o papel reivindicado pela economia dos bens públicos, de ser partícipe das definições que serão tomadas, tendo em vista a provisão de um bem comum, nesse caso eletricidade.

A falta de canais efetivos para que a sociedade manifeste suas preferências em relação à produção e fornecimento da eletricidade são, nesse sentido, a causa dos conflitos vivenciados pelo setor elétrico, no que diz respeito à construção de hidrelétricas. 


\section{REFERÊNCIAS}

AVRITZER, L. Democracy and the public space in Latin America. Princeton: Princeton University Press, 2002.

BANCO MUNDIAL. Licenciamento ambiental de empreendimentos hidrelétricos no Brasil: uma contribuição para o debate. Volume I: Relatório Síntese. [s.n.], 2008.

BERMANN, C. Impasses e controvérsias da hidreletricidade. Estudos . Avançados, v. 21, n. 59, p. 139-153, 1993.

BRASIL, Mercado de Energia elétrica 2006-2015. Rio de Janeiro: EPE, 2005.

BRASIL. Ministério de Minas e Energia. Plano Nacional de Energia 2030. Brasília, DF: MME; EPE, 2007.

CASTRO, E. V. de. Hidrelétricas do Xingu: o Estado contra as sociedades indígenas. In: SANTOS, L. de O.; ANDRADE, L. M. M. As hidrelétricas do Xingu e os povos indígenas. São Paulo: Comissão Pró-Índio, 1988.

CONGRESSO NACIONAL. Constituição da República Federativa do Brasil. Brasília: Congresso Nacional, 1988.

DAGNINO, E. Os movimentos sociais e a emergência de uma nova noção de cidadania. In: DAGNINO, Evelina (Org.). Anos 90 Política e Sociedade no Brasil. São Paulo: Brasiliense, 1994.

Sociedade civil, espaços públicos e construção Democrática no Brasil: limites e possibilidades. In: DAGNINO, E. (org.). Sociedade civil e espaços públicos no Brasil. São Paulo: Paz e Terra, 2002.

MAgAlHÃeS, S. M. S. B.; HERnANDEZ, F. M. (Orgs.). Painel de Especialistas: análise crítica do estudo de impacto ambiental do aproveitamento hidrelétrico de Belo Monte. Belém, 2009.

MILARÉ, E. Direito do Ambiente: doutrina, jurisprudência, glossário. São Paulo: Editora Revista dos Tribunais, 2004.

MINISTERIO PÚBLICO FEDERAL. Deficiências em Estudos de Impacto

Ambiental: síntese de uma experiência. Brasília: Escola Superior do Ministério Público da União, 2004.

OAKERSON, R. The study of local public economies. In: OAKERSON, R. Governing local public economies: creating the civic metropolis. Institute for contemporary studies press: Oakland, California, 1999.

OLIVEIRA, A. I. de A. Introdução à legislação Ambiental Brasileira e Licenciamento Ambiental. Rio de Janeiro: Lumen Júris, 2005.

OSTROM, E. Beyond Markets and States: Polycentric Governance of Complex Economic Systems. American Economic Review, v. 100, p. 641-672, jun. 2010. Disponível em: <http:/ /www.aeaweb.org/articles.php?doi=10.1257/aer.100.3.641>. 
OSTROM, V.; OSTROM, E. Public Goods and Public Choices. In: McGINNIS, M. Policentricity and local public economies: readings from the workshop in Political Theory and Policy Analisys. Michigan: The University of Michigan Press, 1999b. p. $75-103$.

SÁNCHEZ, L. E. Avaliação de impacto ambiental: conceitos e métodos. São Paulo: Oficina de Textos, 2006.

SAUER, I. L. et al. (org.). A reconstrução do setor elétrico brasileiro. São Paulo: Paz e Terra, 2003.

SIGAUD, L. Efeitos sociais de Grandes Projetos hidrelétricos. Rio de Janeiro: Museu Nacional, 1986. (Comunicação, n. 9).

SOUZA, A do N. Licenciamento Ambiental no Brasil sob a perspectiva da modernização ecológica. 2009. Dissertação (Mestrado em Ciência Ambiental) Universidade de São Paulo, São Paulo, 2009. Disponível em: <http://www.teses.usp.br/ teses/disponiveis/90/90131/tde-02112010-233044/>. Acesso em: 27 abr. 2014.

SOUZA, A. do N.; JACOBI, P. R. Hidrelétricas na Amazônia: entre uma nova esfera pública e a modernização ecológica. In: RIBEIRO, W. C. (Org.). Conflitos e cooperação pela água na América Latina. São Paulo: Annablume; PPGH, 2013.

SWITKES, G. Águas turvas: alertas sobre as consequencias de barrar o maior afluente do Amazonas. São Paulo: International Rivers, 2008.

TATAGIBA, L. Os Conselhos Gestores e a democratização das políticas públicas no Brasil. In: DAGNINO, E. (Org). Sociedade civil e espaços públicos no Brasil. São Paulo: Paz e Terra, 2002.

TUNDISI, J. G. et al. How many more dams in the Amazon? Energy Policy, 2014, http://dx.doi.org/10.1016/j. enpol.2014.07.013i

VAINER, C. B. O conceito de Atingido: uma revisão do debate e diretrizes. Rio de Janeiro: IPPUR/UFRJ, 2003.

Recursos hidráulicos: questões sociais e ambientais. Estudos Avançados, v. 21, n. 59. Jan./abr., 2007.

WORLD COMMISSION ON DAMS-WCD. Dams and Development: a new framework for decision-making. The report of the World Commission on DAMS. London: Earthscan, 2000. 
